\title{
BMJ Open Hours lying down per day, as a proxy for sedentary behaviour and risk of diabetes in young and middle-aged adults in Norway: an 11-year follow-up of the HUNT study
}

\author{
Ernest O Asante, ${ }^{1}$ Yi-Qian Sun (D) , ${ }^{2,3}$ Tom Ivar Lund Nilsen, ${ }^{1,4}$ \\ Bjørn Olav Åsvold, ${ }^{5,6,7}$ Elin Pettersen Sørgjerd, ${ }^{7}$ Xiao-Mei Mai (i) ${ }^{1}$
}

To cite: Asante EO, Sun Y-Q, Nilsen TIL, et al. Hours lying down per day, as a proxy for sedentary behaviour and risk of diabetes in young and middle-aged adults in Norway: an 11-year follow-up of the HUNT study. BMJ Open 2020;10:e035010. doi:10.1136/ bmjopen-2019-035010

- Prepublication history and additional material for this paper are available online. To view these files, please visit the journal online (http://dx.doi. org/10.1136/bmjopen-2019035010).

Received 15 0ctober 2019 Revised 19 February 2020 Accepted 04 March 2020
Check for updates

(C) Author(s) (or their employer(s)) 2020. Re-use permitted under CC BY-NC. No commercial re-use. See rights and permissions. Published by BMJ.

For numbered affiliations see end of article.

Correspondence to

Dr Xiao-Mei Mai;

Xiao-Mei.Mai@ntnu.no

\section{ABSTRACT}

Objective We aimed to examine relationship between hours lying down per day, as a proxy for sedentary behaviour and risk of diabetes in young and middle-aged adults, and to assess if leisure-time physical activity and body mass index (BMI) modified this relationship.

Design A population-based prospective cohort study. Setting Nord-Trøndelag, Norway.

Participants The cohort included 17058 diabetes-free adults, at an age of 20-55 years in 1995-1997, who were followed-up to 2006-2008.

Primary outcome measures Incident diabetes was defined by self-report of diabetes or non-fasting glucose levels greater than $11 \mathrm{mmol} / \mathrm{L}$ at the follow-up.

Methods Multivariable logistic regression models were used to obtain OR with $95 \% \mathrm{Cl}$ for risk of diabetes by the categories of hours lying down ( $\leq 7,8$ and $\geq 9$ hours/day). Results 362 individuals (2.1\%) developed diabetes during an average of 11-year follow-up. Individuals who reported lying down $\geq 9$ hours/day had an adjusted OR of 1.35 (95\% $\mathrm{Cl} 1.01$ to 1.80) for incident diabetes compared with those lying down 8 hours/day. Lying down $\leq 7$ hours/day was not associated with the risk of diabetes. In analysis stratified by physical activity, the ORs associated with lying down $\geq 9$ hours/day were 1.41 (95\% $\mathrm{Cl} 1.05$ to 1.90$)$ and 0.90 (95\% $\mathrm{Cl} 0.23$ to 3.55), respectively, among the less active and highly active individuals $\left(\mathrm{p}_{\text {interaction }}=0.048\right)$. There was little evidence that the association differed by BMI status $\left(\mathrm{p}_{\text {interaction }}=0.62\right)$.

Conclusions Prolonged hours lying down per day was associated with an increased risk of diabetes in young and middle-aged adults. The positive association appeared to be modified by physical activity but not by BMI.

\section{BACKGROUND}

The increasing prevalence of diabetes and its continuous inclusion in health policies indicate the significant impact of the disease on populations globally. Research shows a close association of diabetes with onset of cardiovascular diseases, a leading cause of morbidity and mortality in diabetic patients,
Strengths and limitations of this study

- This study of young and middle-aged adults from Central Norway is one of the first population-based studies to provide an insight into potential long-term influence of hours spent lying down on diabetes risk.

- We had comprehensive information on potential confounding factors.

- The size of the population was large, but stratified analysis by leisure-time physical activity showed imprecise result in the highly active group.

- We had no information available to separate hours lying down during the day from the night's sleep.

and there has been a considerable increase in healthcare expenditures on diabetes over the years. ${ }^{1-3}$ Therefore, the need for effective preventive measures has inspired research to look into potential health implications of various lifestyle factors.

A sedentary lifestyle refers to prolonged time spent in behaviours characterised by low muscle movement, which is linked to loss of metabolic health and chronic diseases. ${ }^{4}{ }^{5}$ As such, markers of sedentary behaviours, including total sitting and TV watching time, have shown compelling evidence of a positive association with the development of diabetes. ${ }^{6-8}$

Lying down is characterised with very low energy expenditure. It may be used as an alternative marker for sedentary behaviour and pose an independent health risk. ${ }^{9}$ The detrimental effect of total time spent lying down on cardiovascular health has been highlighted in large prospective cohort studies. ${ }^{10}{ }^{11}$ Higher mortality from cardiovascular diseases was observed among adults who reported prolonged hours lying down per day, even in physically active individuals. ${ }^{10}$ 
Although small-scale experimental studies showed that prolonged bed rest was positively associated with muscle atrophy and insulin resistance, ${ }^{12-14}$ research on potential long-term effect of total hours lying down on diabetes risk at population level has been limited. In addition, it remains unknown if other lifestyle factors such as physical activity and obesity modify the association. These lifestyle factors have shown to modify the association between total sitting time and diabetes risk. ${ }^{15-17}$

The aim of this large prospective cohort study was to investigate the relation between hours lying down per day, as a proxy for sedentary behaviour, and risk of diabetes in young and middle-aged adults in an 11-year follow-up in Norway. Two specific research objectives were undertaken: (1) if longer hours lying down per day were positively associated with the risk of diabetes independently of total sitting time and other risk factors and (2) if leisuretime physical activity or obesity modified the association.

\section{METHODS}

\section{Study population}

The study population was derived from the HUNT study - a large population-based health study conducted in Nord-Trøndelag in Norway. ${ }^{18}$ The HUNT study was conducted in three series. At each survey, healthrelated information of participants was collected by wellstructured questionnaires and a clinical examination. In the present study, we linked data from the HUNT2 survey (1995-1997) to HUNT3 survey (2006-2008) in an average of 11-year follow-up.

Among 65215 adults who participated in HUNT2, 40330 were at 20-55 years of age. The upper age limit was set to 55 years because we were particularly interested in identifying lifestyle factors for prevention of diabetes in young and middle-aged adults. Twenty-five thousand six hundred and sixteen (64\%) of the 40330 adults participated in HUNT3, of which 25282 were diabetes-free at baseline, that is, they reported no diabetes and had a nonfasting blood glucose measurement less than $11 \mathrm{mmol} / \mathrm{L}$ in HUNT2. Among the 25282 diabetes-free adults (study cohort), 17058 (analysis cohort) had complete information on hours spent lying down per day and leisure-time physical activity in HUNT2 as well as information on diabetes in HUNT3. In general, the study and analysis cohorts showed comparable distribution of the baseline variables (see online supplementary table $\mathrm{S} 1$ ).

\section{Main variables}

Participants answered a question 'Do you have, or have you had diabetes?' in both HUNT2 and HUNT3. Among the diabetes-free adults at baseline, incident diabetes cases were identified by self-reporting of diabetes in HUNT3 and/or a non-fasting blood glucose measurement in HUNT3 exceeding $11 \mathrm{mmol} / \mathrm{L}$. Self-reported incident cases were further ascertained by reported age of diagnosis falling between HUNT2 and HUNT3. Individuals without incident diabetes were those who reported no diabetes in HUNT3 and had non-fasting blood glucose measurement in HUNT3 less than $11 \mathrm{mmol} / \mathrm{L}$. Based on serum glutamic acid decarboxylase antibodies (GADA) measured in HUNT3, we classified the incident cases as autoimmune diabetes with an index value of GADA $\geq 0.08,{ }^{19}$ type 2 diabetes with GADA $<0.08$ and an unknown type due to lack of measurement on GADA.

Information on hours lying down per day was obtained from the question 'How many hours do you usually spend lying down during a 24 hours period?' in the HUNT2 questionnaire, in which night's sleep and siesta were specified. The mean and median value of the hours lying down per day in the study cohort was 8 hours. Finer categories of hours lying down were initially generated as $\leq 6,7,8,9$ and $\geq 10$ hours/day. To increase statistical precision, categories were collapsed into $\leq 7,8$ and $\geq 9$ hours/day in main analysis using 8 hours/day as the reference category.

Leisure-time physical activity at baseline was classified into four groups based on a combination of hours of light (no sweat/not out of breath) and vigorous activity (sweat/out of breath) per week: inactive (no activity, or $\leq 2$-hour light activity only), low ( $\geq 3$-hour light activity only, or $\leq 2$ hour light activity and $<1$-hour vigorous activity), moderate ( $\geq 3$-hour light activity and $<1$ hour vigorous activity or 1-2-hour vigorous activity regardless of light activity) and high activity ( $\geq 3$-hour vigorous activity regardless of light activity) ${ }^{20}$ For analysis stratified by leisure-time physical activity, the categories were collapsed into two groups labelled less active (inactive, low and moderate activity) and highly active (high activity).

Height and weight were measured by trained staff during the clinical examination at HUNT2. Body mass index (BMI) was estimated by weight divided by squared value of height and categorised as underweight or normal weight $\left(<25.0 \mathrm{~kg} / \mathrm{m}^{2}\right)$, overweight $\left(25.0-29.9 \mathrm{~kg} / \mathrm{m}^{2}\right)$ and obese $\left(\geq 30.0 \mathrm{~kg} / \mathrm{m}^{2}\right)$ in accordance with WHO recommendation. Data on BMI were collapsed into two groups labelled as non-obese (underweight or normal and overweight) and obese for analysis stratified by BMI.

\section{Other baseline variables}

Other baseline variables were collected by questionnaires, including sex, age (20-29, 30-39, 40-49 and 50-55 years), smoking status (never, ex-smoker, current smoker and missing $0.6 \%$ ), alcohol consumption per month (never, 1-4 times, $\geq 5$ times and missing $1.9 \%$ ), family history of diabetes (yes, no and missing $0.9 \%$ ), chronic diseases (yes, no and missing $2 \%$ ), years of education $(<10,10-12, \geq 13$ years and missing $0.5 \%$ ), economic difficulties (yes, no and missing $1 \%)$, time spent sitting every day $(0-4,5-7$, $\geq 8$ hour and missing $2.9 \%$ ) and type of work (sedentary work, much walking or lifting, heavy physical work, and missing 5.4\%). The following question was used to define chronic disease: 'Do you suffer from any long-term illness or injury of a physical or physiological nature that impairs your functioning in your everyday life?' (long-term means at least 1 year). Economic difficulties were defined as yes when participants reported having difficulties to acquire 
food or transport etc. because of cost. Several other baseline variables were also collected: sleep problems were obtained by question 'During the last month have you woken too early and not been able to get back to sleep?' with four options (almost every night, often, occasionally and never); information on anxiety or depression symptoms was collected as a score using the Hospital Anxiety and Depression Scale (HADS).

\section{Statistical analysis}

Baseline characteristics were presented by categories of hours lying down per day ( $\leq 7,8$ and $\geq 9$ hours/day). In main analysis, logistic regression model was used to estimate crude ORs with 95\% CI for incident diabetes by categories of hours lying down using 8 hours/day as the reference. The adjusted ORs were obtained after adjustment for potential confounding factors including sex, age, BMI, smoking status, alcohol intake per month, family history of diabetes, chronic diseases, education, economic difficulties, total sitting time per day, leisure-time physical activity and type of work. ${ }^{10}{ }^{17}$ Missing information of the covariates was included as a separate category in the analysis. Three sensitivity analyses were performed: (1) BMI, chronic diseases, total sitting time per day, leisure-time physical activity and type of work were left out from the adjustment. This was because BMI and chronic diseases were also possible mediators, and time used in total sitting, leisure physical activity, work and lying down was co-dependent in a day of 24 hours; (2) sleep problems and anxiety and depression symptoms (HADS as a continuous value) were additionally included in the adjustment; (3) we performed analyses using the finer categories of hours lying down and cubic spline regression model to verify the findings from the main analysis. We also calculated the ORs for autoimmune and type 2 diabetes by the three categories of hours lying down using multinomial logistic regression.

The analysis on the relationship between hours lying down per day and risk of diabetes was stratified by leisuretime physical activity (less active vs highly active) and BMI status (non-obese vs obese). Potential statistical interaction was assessed in a likelihood ratio test including a product term of (1) categories of hours lying down $\times$ leisure-time physical activity; and (2) categories of hours lying down $\times \mathrm{BMI}$ in the regression model. All analyses were conducted using STATA/IC V.13.0 for Windows (College Station, Texas, USA).

\section{Patient and public involvement}

There was no patient or public involvement in the design or data analysis of this study.

\section{RESULTS}

The descriptive statistics for the baseline characteristics by categories of hours lying down in the analysis cohort are shown in online supplementary table S2.

A total of $362(2.1 \%)$ individuals were identified with diabetes during the 11-year follow-up period, including 20 with autoimmune diabetes, 307 with type 2 diabetes and 35 with an unknown type due to lack of measurement on GADA. Lying down $\geq 9$ hours/day was associated with an increased diabetes incidence with an adjusted OR of 1.35 (95\% CI 1.01 to 1.80 ), whereas lying down $\leq 7$ hours/ day was not associated with the risk of diabetes in the main analysis (table 1). In the first sensitivity analysis, the OR associated with lying down $\geq 9$ hours/day was $1.44(95 \%$ CI 1.09 to 1.90$)$. In the second sensitivity analysis, the corresponding OR was 1.37 (95\% CI 1.03 to 1.83). The association estimates between lying down $\leq 7$ hours/day and incident diabetes in both sensitivity analyses did not differ from that in the main analysis (data not presented). Results using the finer categories of hours lying down and the cubic spline regression model were consistent with those from the main analysis (online supplementary tables S3 and S4). Lying down $\geq 9$ hours/day was associated with an increased risk for type 2 diabetes (table 2), but the estimated OR for autoimmune diabetes was imprecise due to few cases. Lying down $\leq 7$ hours/day was not associated with either type of diabetes.

Among the less active individuals, lying down $\geq 9$ hours/ day was associated with an increased risk of diabetes with an OR of 1.41 (95\% CI 1.05 to 1.90 ) (table 3). This positive association appeared absent among the highly active individuals $(\mathrm{OR}=0.90,95 \%$ CI 0.23 to 3.55$)$. Lying down $\leq 7$ hours/day was not associated with the risk of diabetes in the less active individuals, but it was associated with a reduced risk in the highly active individuals (table 3 ). A likelihood ratio test showed evidence of statistical

Table 1 Hours lying down per day in relation to incidence of diabetes over an 11-year follow-up ( $n=17058)$

\begin{tabular}{clllll}
\hline $\begin{array}{l}\text { Hours lying } \\
\text { down per day }\end{array}$ & Participants $\mathbf{( n )}$ & Cases (n) & Risk (\%) & $\begin{array}{l}\text { Crude OR } \\
\text { (95\% Cl) }\end{array}$ & $\begin{array}{l}\text { Adjusted OR } \\
(\mathbf{9 5 \%} \text { Cl) }\end{array}$ \\
\hline$\leq 7$ & 6596 & 130 & 2.0 & $0.98(0.77$ to 1.24) & $0.93(0.73$ to 1.18) \\
8 & 7480 & 151 & 2.0 & 1.00 (reference) & 1.00 (reference) \\
$\geq 9$ & 2982 & 81 & 2.7 & $1.36(1.03$ to 1.78) & 1.35 (1.01 to 1.80) \\
\hline
\end{tabular}

Adjusted OR obtained after adjustment for sex, age, body mass index, smoking status, alcohol intake per month, education, economic difficulties, chronic diseases, family history of diabetes, total sitting time, physical activity and type of work. 
Table 2 Hours lying down per day in relation to incidence of autoimmune diabetes or type 2 diabetes over an 11-year followup $\left(n=17058^{\star}\right)$

\begin{tabular}{|c|c|c|c|c|c|}
\hline Hours lying down per day & Participants (n) & Cases (n) & Risk (\%) & $\begin{array}{l}\text { Crude OR } \\
(95 \% \mathrm{Cl})\end{array}$ & $\begin{array}{l}\text { Adjusted OR } \\
(95 \% \mathrm{Cl})\end{array}$ \\
\hline \multicolumn{6}{|l|}{ Autoimmune diabetes $\dagger$} \\
\hline$\leq 7$ & 6596 & 7 & 0.1 & 0.72 (0.28 to 1.86$)$ & 0.69 (0.26 to 1.83$)$ \\
\hline 8 & 7480 & 11 & 0.2 & 1.00 (reference) & 1.00 (reference) \\
\hline$\geq 9$ & 2982 & 2 & 0.1 & 0.46 (0.10 to 2.07$)$ & $0.53(0.12$ to 2.47$)$ \\
\hline \multicolumn{6}{|l|}{ Type 2 diabetes $\ddagger$} \\
\hline$\leq 7$ & 6596 & 112 & 1.7 & 1.05 (0.81 to 1.36$)$ & 0.99 (0.76 to 1.30$)$ \\
\hline 8 & 7480 & 121 & 1.6 & 1.00 (reference) & 1.00 (reference) \\
\hline$\geq 9$ & 2982 & 74 & 2.5 & 1.55 (1.15 to 2.07$)$ & 1.54 (1.13 to 2.09 ) \\
\hline
\end{tabular}

Adjusted OR obtained after adjustment for sex, age, body mass index, smoking status, alcohol intake per month, education, economic difficulties, chronic diseases, family history of diabetes, total sitting time, physical activity and type of work.

*Data not presented for 35 incident diabetes cases with an unknown type due to lack of measurement on glutamic acid decarboxylase antibodies (GADA).

†Autoimmune diabetes: incident diabetes cases with an index value of GADA $\geq 0.08$.

$\ddagger$ Type 2 diabetes: incident diabetes cases with GADA $<0.08$.

interaction between hours lying down per day and leisuretime physical activity $\left(\mathrm{p}_{\text {interaction }}=0.048\right)$.

Among the obese individuals, lying down $\geq 9$ hours/ day was associated with an increased risk of diabetes (OR=1.61, 95\% CI 1.04 to 2.49) (table 4). It was also associated with an increased OR among the non-obese individuals $(\mathrm{OR}=1.23,95 \% \mathrm{CI} 0.83$ to 1.82$)$. There was little evidence of statistical interaction between hours lying down and BMI ( $\left.\mathrm{p}_{\text {interaction }}=0.62\right)$.

\section{DISCUSSION}

We observed a $35 \%$ higher risk of incident diabetes in people reporting lying down $\geq 9$ hours / day compared with those lying down 8 hours/day. Lying down $\leq 7$ hours/day was not associated with the diabetes risk. Stratified analysis showed that lying down $\geq 9$ hours / day was associated with diabetes risk in the less physically active group but not in the highly active group. There was little evidence that BMI modified the association.

\section{Prolonged hours lying down as an independent risk factor for diabetes}

Results of the present study are in accordance with a metaanalysis study in which a positive association was found between prolonged sitting behaviour and increased risk of diabetes. ${ }^{21}$ The more recent studies have also demonstrated a positive association between total sitting time and diabetes risk. ${ }^{617}$ After adjustment for sitting time and other risk factors in the present study, lying down $\geq 9$ hours/day

Table 3 Hours lying down per day in relation to incidence of diabetes over an 11-year follow-up stratified by leisure-time physical activity $(n=17058)$

\begin{tabular}{|c|c|c|c|c|c|}
\hline Hours lying down per day & Participants (n) & Cases (n) & Risk (\%) & $\begin{array}{l}\text { Crude OR } \\
(95 \% \mathrm{Cl})\end{array}$ & $\begin{array}{l}\text { Adjusted OR } \\
(95 \% \mathrm{Cl})\end{array}$ \\
\hline \multicolumn{6}{|l|}{ Less active* } \\
\hline 8 & 6534 & 138 & 2.1 & 1.00 (reference) & 1.00 (reference) \\
\hline$\geq 9$ & 2623 & 78 & 3.0 & $1.42(1.07$ to 1.88$)$ & 1.41 (1.05 to 1.90$)$ \\
\hline \multicolumn{6}{|l|}{ Highly active† } \\
\hline 8 & 946 & 13 & 1.4 & 1.00 (reference) & 1.00 (reference) \\
\hline$\geq 9$ & 359 & 3 & 0.8 & $0.60(0.17$ to 2.13$)$ & $0.90(0.23$ to 3.55$)$ \\
\hline
\end{tabular}

Adjusted OR obtained after adjustment for sex, age, body mass index, smoking status, alcohol intake per month, education, economic difficulties, chronic diseases, family history of diabetes, total sitting time and type of work.

*Less active refers to inactive and low-to-moderate physical activity.

†Highly active refers to high levels of physical activity. 
Table 4 Hours lying down per day in relation to incidence of diabetes over an 11-year follow-up stratified by BMI status ( $\mathrm{n}=17$ $\left.024^{*}\right)$

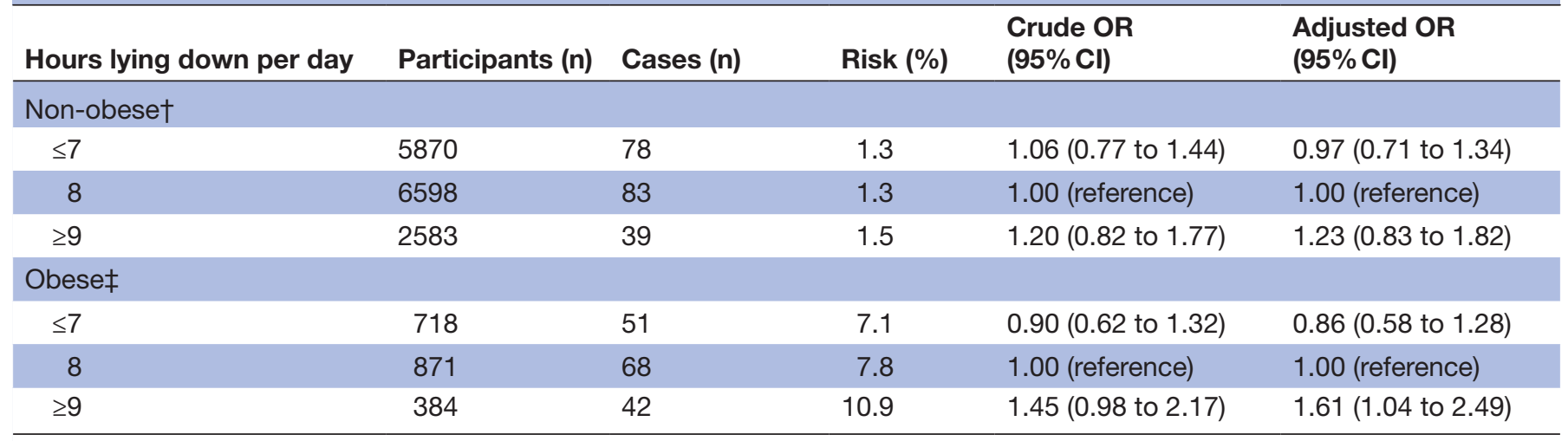

Adjusted OR obtained after adjustment for sex, age, smoking status, alcohol intake per month, education, economic difficulties, chronic diseases, family history of diabetes, total sitting time, physical activity and type of work.

*Thirty-four participants are not included due to missing information on BMI.

$\dagger$ Non-obese refers to $\mathrm{BMI}<30.0 \mathrm{~kg} / \mathrm{m}^{2}$.

$\ddagger$ Obese refers to $\mathrm{BMI} \geq 30.0 \mathrm{~kg} / \mathrm{m}^{2}$.

BMI, body mass index.

was independently associated with a moderate increase in diabetes risk. In a previous HUNT study, prolonged hours lying down was independently associated with mortality from all-cause and cardiovascular disease. ${ }^{10}$

Skeletal muscles function as a key site for insulinstimulated glucose disposal, and loss in muscles associated with sedentary behaviour may contribute to pathogenesis of diabetes in adults. ${ }^{22}$ Studies have also observed rapid decrease of muscle glucose transporter (GLUT) proteins when muscles are not used. ${ }^{23}$ Low levels and expression of the GLUT-proteins affect carbohydrate metabolism and contribute to insulin resistance in the skeletal muscles. ${ }^{23-25}$ In addition, low energy expenditure associated with sedentary behaviour may have negative impact on lipid levels leading to lipids accumulation and insulin resistance. ${ }^{26}{ }^{27}$ In a broader perspective, all these mechanisms may result in increased levels of glucose, lipids and other metabolic markers that contribute to metabolic syndrome. ${ }^{28}$ Prolonged sitting time has been strongly linked with metabolic impairment, ${ }^{28} 29$ which predisposes individuals to high diabetes risk in the long term. The energy expenditure associated with lying down is very low. Compared with sitting, there is a decrease in heart rate and respiratory quotient associated with lying down. ${ }^{30}$ Therefore, a detrimental effect of longer hours lying down on risk of diabetes can be anticipated.

\section{Influence of physical activity on the association}

Our findings are consistent with previous studies in which physical activity modified the association between prolonged sitting time and incident diabetes or mortality, ${ }^{15} 1731$ with a positive association remained in the inactive individuals but disappeared in the active individuals. Nevertheless, the potential adverse effect of prolonged lying down on mortality has been shown to exist among both active and inactive people in a previous HUNT study. ${ }^{10}$ In the referred study, ${ }^{10}$ active individuals were categorised as those who reported moderate-tohigh levels of physical activity, which may explain why harmful effect of longer hours lying down remained in the physically active group. Our study suggested that high levels of physical activity might have an interaction with prolonged hours lying down on the risk of diabetes. In practice, moderate level of physical activity in the HUNT studies aligns with the physical activity recommendations for public health. ${ }^{31}{ }^{32}$ Ekelund et al in their meta-analysis found physical activity beyond recommended levels being capable of cancelling out the risk of death associated with prolonged sitting. ${ }^{31}$

It is well documented that physical activity increases glucose uptake and improves glucose homeostasis and overall energy balance. ${ }^{3-36}$ Highly active individuals engage in more vigorous activity compared with the less active individuals. High intensity training has been shown to increase glucose uptake during and post exercise. ${ }^{25} 3738$ Engaging in vigorous physical activity also provides a better lipid profile that may help to prevent insulin resistance. ${ }^{39} 40$ Therefore, highly active individuals may have an advantage with higher insulin sensitivity and glucose metabolism during longer hours lying down to prevent or delay the onset of diabetes. Less active individuals with little or no vigorous physical activity may have an excess metabolic risk from prolonged lying down.

\section{Influence of obesity on the association}

Studies suggest that sedentary behaviour and obesity may have a bidirectional relationship. ${ }^{41-43}$ Obesity may be either a confounding factor or an intermediate factor in the context. ${ }^{44}$ Adjustment for a potential intermediate factor would bias the association between sedentary behaviour and health outcome towards null. ${ }^{44}$ Thus, if obesity is a mediator, the magnitude of association between longer hours lying down and risk of diabetes may have been underestimated in the main result (OR 1.35). 
Similar to a previous HUNT study on total sitting time in relation to diabetes risk, ${ }^{17}$ there was little evidence of statistical interaction by BMI status in the present study. This was inconsistent with two other studies that reported an interaction between BMI and sitting time on risk of diabetes. ${ }^{15} 16$ However, the latter studies either used self-reported height and weight or conducted in postmenopausal women.

\section{Strengths and weaknesses}

This prospective cohort study of young and middle-aged adults from Central Norway is one of the first populationbased studies to provide an insight into the potential longterm influence of hours spent lying down on diabetes risk. The distribution of baseline characteristics was similar in the study and analysis cohorts. In addition, comprehensive information on potential confounding factors warranted more accurate estimate for the association.

There are several limitations with the study. Selection bias cannot completely be excluded as $64 \%$ of the young and middle-aged adults in HUNT2 were followed-up in HUNT3. However, the participation rate did not differ substantially among adults who reported lying down $\leq 7$, 8 and $\geq 9$ hours/day (66\%, 68\% and $61 \%$, respectively). The size of the population was large, but stratified analysis showed imprecise result in the highly physically active group. Self-reported information on hours lying down, diabetes and covariates are subject to misclassification that is likely to be non-differential in a prospective study. Moreover, we cannot rule out residual confounding due to unknown or unmeasured factors, for example the lack of dietary information. We are also unable to conclude if prolonged hours lying down was associated with an increased risk of autoimmune diabetes due to few cases. Finally, hours spent lying down per day in our study included night's sleep. We did not have information on duration of night's sleep specifically. Both short and long sleep have been reported to increase mortality and risk of diabetes in previous studies. ${ }^{45} 46$ The harm of short sleep may be explained by consequences of sleep problems per se; the harm of long sleep is suggested to be explained by chronic diseases and depression. ${ }^{45}$ Our data showed that adjustment for chronic diseases in the main analysis and additional adjustment for sleep problems, and anxiety and depression symptoms in the sensitivity analysis did not change the observed association between prolonged hours lying down and risk of diabetes. In addition, we did not observe that shorter hours lying down per day were associated with an increased risk of diabetes. All these suggested that our exposure variable was less likely to be a proxy for sleep duration.

\section{CONCLUSIONS}

Prolonged hours lying down per day, as a proxy for sedentary behaviour, was associated with an increased risk of diabetes in a young and middle-aged adult population. The positive association was present in the less physically active individuals, but it appeared absent among the highly active individuals. The association did not differ by BMI status.

\section{Author affiliations}

${ }^{1}$ Department of Public Health and Nursing, Norwegian University of Science and Technology, Trondheim, Norway

${ }^{2}$ Department of Clinical and Molecular Medicine, Norwegian University of Science and Technology, Trondheim, Norway

${ }^{3}$ TkMidt-Center for Oral Health Services and Research, Trondheim, Norway ${ }^{4}$ Clinic of Anesthesia and Intensive Care, St. Olavs Hospital, Trondheim University Hospital, Trondheim, Norway

${ }^{5}$ K.G. Jebsen Center for Genetic Epidemiology, Department of Public Health and Nursing, Norwegian University of Science and Technology, Trondheim, Norway ${ }^{6}$ Department of Endocrinology, St. Olavs Hospital, Trondheim University Hospital, Trondheim, Norway

${ }^{7}$ HUNT Research Centre, Department of Public Health and Nursing, The Norwegian University of Science and Technology, Levanger, Norway

Acknowledgements The HUNT Study is a collaboration between the HUNT Research Centre (Faculty of Medicine and Health Sciences, NTNU, Norwegian University of Science and Technology), the Nord-Trøndelag County Council, Central Norway Regional Health Authority and the Norwegian Institute of Public Health.

Contributors EOA and X-MM contributed to the study design and conducted statistical analysis and wrote the initial draft of the manuscript. Y-QS, TILN, BOA and EPS contributed to the interpretation of results and critically revised the manuscript for important intellectual content. All authors approved the final version of the manuscript.

Funding This work was supported by Department of Public Health and Nursing, NTNU (EOA) and The Norwegian Cancer Society [project ID 5769155-2015] (Y-QS) and The Research Council of Norway "Gaveforsterkning" (Y-QS).

Competing interests None declared.

Patient consent for publication Not required.

Ethics approval The study was approved by the Norwegian Regional Committees for Medical and Health Research Ethics (2010/389/REK midt).

Provenance and peer review Not commissioned; externally peer reviewed.

Data availability statement Data are available upon reasonable request. Data from the HUNT Study that is used in research projects will, when reasonably requested by others, be made available on request to the HUNT Data Access Committee (hunt@medisin.ntnu.no). The HUNT data access information describes the policy regarding data availability (https://www.ntnu.edu/hunt/data).

Open access This is an open access article distributed in accordance with the Creative Commons Attribution Non Commercial (CC BY-NC 4.0) license, which permits others to distribute, remix, adapt, build upon this work non-commercially, and license their derivative works on different terms, provided the original work is properly cited, appropriate credit is given, any changes made indicated, and the use is non-commercial. See: http://creativecommons.org/licenses/by-nc/4.0/.

ORCID iDs

Yi-Qian Sun http://orcid.org/0000-0002-9634-9236

Xiao-Mei Mai http://orcid.org/0000-0002-0426-7496

\section{REFERENCES}

1 Leon BM, Maddox TM. Diabetes and cardiovascular disease: epidemiology, biological mechanisms, treatment recommendations and future research. World J Diabetes 2015;6:1246-58.

2 Tamayo T, Rosenbauer J, Wild SH, et al. Diabetes in Europe: an update. Diabetes Res Clin Pract 2014;103:206-17.

3 Sørensen M, Arneberg F, Line TM, et al. Cost of diabetes in Norway 2011. Diabetes Res Clin Pract 2016;122:124-32.

4 Wolfe RR. The underappreciated role of muscle in health and disease. Am J Clin Nutr 2006;84:475-82.

5 Steene-Johannessen J, Anderssen SA, Kolle E, et al. Low muscle fitness is associated with metabolic risk in youth. Med Sci Sports Exerc 2009;41:1361-7.

6 van der Berg JD, Stehouwer CDA, Bosma H, et al. Associations of total amount and patterns of sedentary behaviour with type 
2 diabetes and the metabolic syndrome: the Maastricht study. Diabetologia 2016;59:709-18.

7 Grøntved A, Hu FB. Television viewing and risk of type 2 diabetes, cardiovascular disease, and all-cause mortality: a meta-analysis. JAMA 2011;305:2448-55.

8 Henson J, Dunstan DW, Davies MJ, et al. Sedentary behaviour as a new behavioural target in the prevention and treatment of type 2 diabetes. Diabetes Metab Res Rev 2016;32:213-20.

9 Ainsworth BE, Haskell WL, Whitt MC, et al. Compendium of physical activities: an update of activity codes and MET intensities. Med Sci Sports Exerc 2000;32:S498-516.

10 Holtermann A, Mork PJ, Nilsen TIL. Hours lying down per day and mortality from all-causes and cardiovascular disease: the HUNT study, Norway. Eur J Epidemiol 2014;29:559-65.

11 McDermott MM, Guralnik JM, Ferrucci L, et al. Community walking speed, sedentary or lying down time, and mortality in peripheral artery disease. Vasc Med 2016;21:120-9.

12 Dirks ML, Wall BT, van de Valk B, et al. One week of bed rest leads to substantial muscle atrophy and induces whole-body insulin resistance in the absence of skeletal muscle lipid accumulation. Diabetes 2016;65:2862-75.

13 Kenny HC, Rudwill F, Breen L, et al. Bed rest and resistive vibration exercise unveil novel links between skeletal muscle mitochondria function and insulin resistance. Diabetologia 2017;60:1491-501.

14 Alibegovic AC, Højbjerre L, Sonne MP, et al. Impact of 9 days of bed rest on hepatic and peripheral insulin action, insulin secretion, and whole-body lipolysis in healthy young male offspring of patients with type 2 diabetes. Diabetes 2009;58:2749-56.

15 Petersen CB, Bauman A, Tolstrup JS. Total sitting time and the risk of incident diabetes in Danish adults (the DANHES cohort) over 5 years: a prospective study. Br J Sports Med 2016:50:1382-7.

16 Manini TM, Lamonte MJ, Seguin RA, et al. Modifying effect of obesity on the association between sitting and incident diabetes in postmenopausal women. Obesity 2014;22:1133-41.

17 Åsvold BO, Midthjell K, Krokstad S, et al. Prolonged sitting may increase diabetes risk in physically inactive individuals: an 11 year follow-up of the HUNT Study, Norway. Diabetologia 2017;60:830-5.

18 Krokstad S, Langhammer A, Hveem K, et al. Cohort profile: the HUNT study, Norway. Int J Epidemiol 2013;42:968-77.

19 Sørgjerd EP, Skorpen F, Kvaløy K, et al. Time dynamics of autoantibodies are coupled to phenotypes and add to the heterogeneity of autoimmune diabetes in adults: the HUNT study, Norway. Diabetologia 2012;55:1310-8.

20 Jiang L, Sun Y-Q, Brumpton BM, et al. Prolonged sitting, its combination with physical inactivity and incidence of lung cancer: prospective data from the HUNT study. Front Oncol 2019;9:101.

21 Wilmot EG, Edwardson CL, Achana FA, et al. Sedentary time in adults and the association with diabetes, cardiovascular disease and death: systematic review and meta-analysis. Diabetologia 2012;55:2895-905.

22 DeFronzo RA, Tripathy D. Skeletal muscle insulin resistance is the primary defect in type 2 diabetes. Diabetes Care 2009;32:S157-63.

23 Tremblay MS, Colley RC, Saunders TJ, et al. Physiological and health implications of a sedentary lifestyle. Appl Physiol Nutr Metab 2010;35:725-40.

24 Bergouignan A, Rudwill F, Simon C, et al. Physical inactivity as the culprit of metabolic inflexibility: evidence from bed-rest studies. $J$ Appl Physiol 2011;111:1201-10.

25 Richter EA, Hargreaves M. Exercise, GLUT4, and skeletal muscle glucose uptake. Physiol Rev 2013;93:993-1017.
26 Kelley DE, Goodpaster BH. Skeletal muscle triglyceride. An aspect of regional adiposity and insulin resistance. Diabetes Care 2001;24:933-41.

27 Corcoran MP, Lamon-Fava S, Fielding RA. Skeletal muscle lipid deposition and insulin resistance: effect of dietary fatty acids and exercise. Am J Clin Nutr 2007;85:662-77.

28 Edwardson CL, Gorely T, Davies MJ, et al. Association of sedentary behaviour with metabolic syndrome: a meta-analysis. PLoS One 2012;7:e34916.

29 Dunstan DW, Kingwell BA, Larsen R, et al. Breaking up prolonged sitting reduces postprandial glucose and insulin responses. Diabetes Care 2012;35:976-83.

30 Miles-Chan JL, Sarafian D, Montani JP, et al. Sitting comfortably versus lying down: is there really a difference in energy expenditure? Clin Nutr 2014;33:175-8.

31 Ekelund U, Steene-Johannessen J, Brown WJ, et al. Does physical activity attenuate, or even eliminate, the detrimental association of sitting time with mortality? A harmonised metaanalysis of data from more than 1 million men and women. Lancet 2016;388:1302-10.

32 WHO. Global recommendations on physical activity for health 2010.

33 Horsch A, Wobmann M, Kriemler S, et al. Impact of physical activity on energy balance, food intake and choice in normal weight and obese children in the setting of acute social stress: a randomized controlled trial. BMC Pediatr 2015;15:12.

34 van Baak MA. Physical activity and energy balance. Public Health Nutr 1999;2:335-9.

35 Sylow L, Kleinert M, Richter EA, et al. Exercise-stimulated glucose uptake - regulation and implications for glycaemic control. Nat Rev Endocrinol 2017;13:133-48.

36 Rottensteiner M, Leskinen T, Niskanen E, et al. Physical activity, fitness, glucose homeostasis, and brain morphology in twins. Med Sci Sports Exerc 2015;47:509-18.

37 Adams OP. The impact of brief high-intensity exercise on blood glucose levels. Diabetes Metab Syndr Obes 2013;6:113-22.

38 Gibala MJ, Little JP, Macdonald MJ, et al. Physiological adaptations to low-volume, high-intensity interval training in health and disease. $J$ Physiol 2012;590:1077-84.

39 Zheng $\mathrm{S}$, $\mathrm{Xu} \mathrm{H}$, Zhou H, et al. Associations of lipid profiles with insulin resistance and $\beta$ cell function in adults with normal glucose tolerance and different categories of impaired glucose regulation. PLoS One 2017;12:e0172221.

$40 \mathrm{Kwon} \mathrm{H}-\mathrm{J}$, Lee $\mathrm{H}-\mathrm{J}$. Effect of vigorous physical activity on blood lipid and glucose. J Exerc Rehabil 2017;13:653-8.

41 Pedisic Z, Grunseit A, Ding D, et al. High sitting time or obesity: which came first? Bidirectional association in a longitudinal study of 31,787 Australian adults. Obesity 2014;22:2126-30.

42 Bullock VE, Griffiths P, Sherar LB, et al. Sitting time and obesity in a sample of adults from Europe and the USA. Ann Hum Biol 2017:44:230-6.

43 Heinonen I, Helajärvi H, Pahkala K, et al. Sedentary behaviours and obesity in adults: the cardiovascular risk in young Finns study. BMJ Open 2013;3:e002901.

44 Hamilton MT, Hamilton DG, Zderic TW. Sedentary behavior as a mediator of type 2 diabetes. Med Sport Sci 2014;60:11-26.

45 Gallicchio L, Kalesan B. Sleep duration and mortality: a systematic review and meta-analysis. J Sleep Res 2009;18:148-58.

46 Shan Z, Ma H, Xie M, et al. Sleep duration and risk of type 2 diabetes: a meta-analysis of prospective studies. Diabetes Care 2015;38:529-37. 